\title{
Social Media Use, Engagement and Addiction as Predictors of Academic Performance
}

\author{
Jamal J. Al-Menayes ${ }^{1}$ \\ ${ }^{1}$ Department of Mass Communication, Kuwait University, Kuwait \\ Correspondence: Jamal J. Al-Menayes, Department of Mass Communication, Kuwait University, Kuwait. Tel: \\ 965-24-81-6790. E-mail: jamal@almenayes.com
}

Received: October 12, 2015

Accepted: October 25, 2015 Online Published: November 10, 2015

doi:10.5539/ijps.v7n4p86

URL: http://dx.doi.org/10.5539/ijps.v7n4p86

\begin{abstract}
This study investigated the effect of social media usage, engagement, and addiction on academic performance. First, the results show that the amount of time one spends using social media affects academic performance in a negative way. The amount of time one spends using social media is negatively correlated with their academic performance. Second, the study examined the effect of social media engagement on academic performance. Results show the SMEQ had no significant impact on academic performance. This outcome indicates that, unlike social media usage, being engaged alone does not affect academic performance. Finally, the study looked at social media addiction and its effect on academic performance. Social Media Addiction Scale (SMAS) was used for this purpose. Factor analysis was again used to determine the dimensions of SMAS. The analysis yielded three factors. Two of these factors were negative predictors of academic performance. This is not surprising since addiction implies heavy usage that previously showed the same negative effect on academic performance.
\end{abstract}

Keywords: social media, addiction, academic performance, Kuwait

\section{Introduction}

The pervasiveness of social media, such as Twitter, Instagram, and SnapChat continues to rise affording people remarkable opportunities to communicate through social networks (Nadkarni \& Hoffman, 2012; Junco, 2013). Many people are taking advantage of these opportunities by spending considerable time on social media (Schulze, Scholer, \& Skiera, 2014). For example, a survey of 3000 students from across the US found that $90 \%$ of university students use Facebook and 37\% use Twitter (Dahlstrom, de Boor, Grunwaald, \& Vokley, 2011). With their popularity, some universities are using social media to market programs and communicate with students, both current and prospective and alumni. Some professors are beginning to use social media with the goal of enhancing the educational process and teamwork on projects and improving learning outcomes through better communication with students. However, some recent studies have found that over-involvement with social media by students can have adverse effects on academic performance (Al-Menayes, 2014; Skiera, Hinz, \& Martin-Span, 2015). This has prompted discussion among educators from various academic fields about the usefulness and viability of social media as a teaching tool.

To clarify how social media activities affect academic performance, this study will analyze the relationship between academic performance and various measures of social media activity. To accomplish this aim, I will use cross-sectional data collected from students in a large public university. This will hopefully help us shed some light on the interaction between social media activity and academic performance.

\section{Literature Review}

Previous studies on social media activity and academic performance is growing, but still relatively in short supply and concentrated on U.S. students. Table 1 summarizes the research findings to date. Despite some variation, most studies found a negative relation between time spent using social media and academic performance. Almost all of these studies rely on self-reported, cross-sectional, grade based data. The independent variable in most of these is time spent using social media (See Junco, 2012). 
Table 1. Previous research on the relationship between social media usage and academic performance

\begin{tabular}{|c|c|c|c|}
\hline Study & Major Finding & $\begin{array}{l}\text { Measure of Academic } \\
\text { Performance }\end{array}$ & $\begin{array}{l}\text { Measure of Social } \\
\text { Media Usage }\end{array}$ \\
\hline $\begin{array}{l}\text { Pasek, More and } \\
\text { Hargiatti (2009) }\end{array}$ & $\begin{array}{l}\text { No connection between } \\
\text { Facebook usage and } \\
\text { academic performance }\end{array}$ & Self-reported GPA & $\begin{array}{l}\text { Self-reported binary } \\
\text { measure of Facebook } \\
\text { usage }\end{array}$ \\
\hline $\begin{array}{l}\text { Kirschner and } \\
\text { Karpinski } \\
(2010)\end{array}$ & $\begin{array}{lr}\text { Negative } & \text { relation } \\
\text { between Facebook usage } \\
\text { and } \\
\text { performance }\end{array}$ & Self-reported GPA & $\begin{array}{l}\text { Self-reported measure } \\
\text { of Facebook usage }\end{array}$ \\
\hline $\begin{array}{l}\text { Jacobsen and } \\
\text { Forste }(2011)\end{array}$ & $\begin{array}{l}\text { Negative relation } \\
\text { between social networks } \\
\text { exposure and academic } \\
\text { performance }\end{array}$ & Self-reported GPA & $\begin{array}{l}\text { Self-reported time-diary } \\
\text { on use usage of } \\
\text { electronic media }\end{array}$ \\
\hline Junco (2012) & $\begin{array}{l}\text { Negative relation } \\
\text { between Facebook usage } \\
\text { time and academic } \\
\text { performance }\end{array}$ & $\begin{array}{l}\text { GPA obtained from } \\
\text { university records }\end{array}$ & $\begin{array}{l}\text { Self-reported time spent } \\
\text { on Facebook }\end{array}$ \\
\hline $\begin{array}{l}\text { Paul, Baker and } \\
\text { Cochran (2012) }\end{array}$ & $\begin{array}{l}\text { Negative relation } \\
\text { between social networks } \\
\text { usage time and academic } \\
\text { performance }\end{array}$ & Self-reported GPA & $\begin{array}{l}\text { Self-reported time spent } \\
\text { on social networks }\end{array}$ \\
\hline $\begin{array}{l}\text { Karpinski, } \\
\text { Kirschner, Ozer, } \\
\text { Mellott and } \\
\text { Ochwo (2013) }\end{array}$ & $\begin{array}{ll}\text { Negative } & \text { relation } \\
\text { between social networks } \\
\text { usage and academic } \\
\text { performance }\end{array}$ & Self-reported GPA & $\begin{array}{l}\text { Self-reported measure } \\
\text { of social media usage }\end{array}$ \\
\hline $\begin{array}{l}\text { Al-Menayes } \\
(2014)\end{array}$ & $\begin{array}{l}\text { Negative relation } \\
\text { between time spent using } \\
\text { social media and } \\
\text { academic performance }\end{array}$ & Self-reported GPA & $\begin{array}{l}\text { Self-reported time spent } \\
\text { on social media }\end{array}$ \\
\hline
\end{tabular}

Note. $\overline{\mathrm{GPA}}=$ Grade Point Average.

In their research specially designed to study multi-tasking and academic achievement, Junco and Cotton (2011) looked at large samples of college students and discovered that sending text messages and using Facebook while studying or doing homework were commonplace. Furthermore, this behavior hindered their study and was negatively correlated to overall college GPA (Junco \& Cotton, 2012). Wood et al. (2012) examined the effect of multi-tasking with several media technologies (texting, e-mail, MSN messaging, Facebook) on real-time learning. Subjects were randomly assigned to different situations (multi-tasking with one of the four technologies or no multitasking) while taking place in classroom setting. After they had finished the learning tasks, the students were given a 15 -item multiple choice test to assess learning. Results showed that multi-tasking with any of the assigned technologies is negatively related to learning.

More recently, Rosen et al. (2013) studied the behavior of middle school, high school and college students and observed that participants were distracted by media like Facebook and texting in less than 6 minutes after the start of a studying session. In addition, measurements of daily Facebook use and texting behavior were strong predictors of off-task behavior during study periods. More importantly, all of the media related technologies associated with increases in multi-tasking and decrease in academic achievement is now commonly accessed with a single Internet-enabled mobile phone. 


\section{Social Media Addiction}

While none of the earlier studies addressed the use of mobile social media per se, it is safe to say the results of computer related Internet addiction also apply to mobile Internet since they both essentially use the same medium. The introduction of anytime, anywhere Wi-Fi in mobile phones and the pervasiveness of free social media apps made them impossible to differentiate from personal computers when it came to Internet addiction. Also, as their name indicates, mobile phones are portable allowing trouble-free access to the Internet irrespective of time and place. Portability makes them the perfect medium for Internet addicts.

Mobile social media present a large number of experiences from a psychological perspective, each with potential that can result in problematic behavioral patterns. For instance, a socially inclined person might expend much time on Facebook, repeatedly checking their profile to have a glimpse of the number of "likes" their latest post got from viewers. Others, with a narcissistic inclination, may find Instagram to be an addictive arena for them to present themselves to others with "selfies". Another fuel for social media addiction may be social anxiety. The fear of missing out (FoMO) offers an explanation for frequent social media any time of day at the expense of other activities (Przybylski et al., 2013).

"Mobile phone addiction" is sometimes used to differentiate it from the construct of Internet addiction. Past studies of online addiction did not address problematic mobile phone use. Mobile phones today offer access to almost all Internet applications along with voice and video calls, text messaging, video recording. In addition, there are numerous engaging apps intended especially for small screens, but their results can also be shown on any screen. Also, they have the added element of being always accessible, an attribute qualitatively different from the traditional personal computer in all of its forms and sizes.

Mobile phones can be used while strolling, traveling in buses or trains and even while driving a car. These "micro time slots" in which people can take part in numerous online activities were not available just a decade ago. Micro time slots can lead to obsessive mobile phone usage and can interfere with face-to-face interaction and harm academic performance (Almenayes, 2014).

Studies of problematic mobile media usage are far and few in between, but the phenomenon has garnered mounting interest in recent times. Research conducted in Taiwan on female college students, for example, revealed that students, who received high scores on an assessment of mobile phone addiction, exhibited more extraversion and anxiety, and somewhat lower self-esteem (Fu-Yuan \& Chiu, 2012). Women seem to be more susceptible to mobile phone addiction than men.

Another aspect of mobile phones that may have a significant implication for addictive behavior is "texting" whether directly or by using social media such as Whatsapp and comparable applications. The latest studies reveal that young individuals are beginning to discard Facebook and choose Twitter instead, especially as their parents started to utilize the former and ask their children to interact with them (Madden et al., 2013). These kinds of applications are on the rise, enabling a large number of features like Vine, which enables clients to make six-second videos to display to their followers. The common characteristic of these applications is their "stickiness", the proclivity to have users utilize the app regularly. Stickiness is a feature of their business models that rely on the heap of data on user activities to share with business clients for segment-specific selling of goods and services.

Given the above, this study seeks to shed light on the relationship between social media usage and academic performance. More specifically, it will try to answer three questions about the relationship between social media activity and academic performance. Three measures will be used to reflect activity; time spent using social media, social media engagement, and social media addiction. Using survey data, the current study will attempt to answer questions about the relationship between mobile social media use and academic performance specified in the following questions.

\section{Research Questions}

RQ1: What is the effect of Social Media usage on academic performance?

RQ2: What is the effect of Social Media Engagement on academic performance?

RQ3: What is the effect of Social Media Addiction on academic performance? 


\section{Method}

\subsection{Sample and Procedures}

The study relied on a survey data where respondends filled out a paper questionnaire. The data were collected from a sample of purposively selected college students reflecting the fact that youth constitue the majority of social media users. College students enrolled in mass communication courses at a large state university were asked to take part in this study. The questionnaires were circulated over a span of three months beginning in March 2014. The final sample size was 1327. The language used in the queationnaire was Arabic.

The responses were both anonymous and confedential, and students were free not to take part in the survey if they wish. The participants age ranged from 18 to 31 with $96 \%$ falling in the 18 to 25 years range. The mean age 21.87 years. The sample consisted of $396(29.8 \%)$ males and 931 (70.2\%) females. The gender sample distribution is reflective of the enrollment profile of the university students which is $70 \%$ female. Lastly, because this is a public university, the vast majority of students are Kuwaiti nationals by law, so recording their nationality was not necessary. The questionnaires were distributed during regular class sessions. The instrument included Likert scale questions, used to measure the individual's perceptions, attitudes and behaviors, as well as demographic questions and questions about media use behavior.

\subsection{Measurement}

Sex

Sex was recorded as a dummy variable with (0) for male and (1) for female.

\section{GPA}

Participants were asked to report their cumulative GPA as of the day they filled out the questionnaire. The maximum is 4.0 .

\section{Time Spent Using Social Media Per Day}

Respondents were asked a single question about the total number of hours spent using social media daily on an eight-point scale: (1) less than two hours, (2) from two to 4 hours, (3) from 4 to 6 hours, (4) from 6 to eight hours, (5) from eight to 10 hours, (6) from 10 to 12 hours, (7) from 12 to 14 hours, (8) more than 14 hours.

\subsection{Social Media Addiction}

To measure social media addiction, a variant of the Internet Addiction Internet Addiction Test (IAT) (Young, 2009). It is called Social Media Addiction Scale (SMAS). The SMAS consisted of 14 items adapted from the IAT to fit the context of social media usage. The items were rated on a five-point Likert scale: strongly agree, agree, neutral, disagree, strongly disagree, scored $5,4,3,2$, and 1 respectively.The sample size is sufficient for a scale consisting of 14 items. Table 2 shows the wording of all fourteen items in addition to the means and standard deviations.

Table 2. Wording of the social media addiction items included in the factor analysis (Original in Arabic)

1. I often find myself using social media longer than intended.

2. I often find life to be boring without social media.

3. I often neglect my schoolwork because of my usage of social media.

4. I get irritated when someone interrupts me when I'm using social media.

5. Several days could pass without me feeling the need to use social media.

6. Time passes by without me feeling it when I am using social media.

7. I find it difficult to sleep shortly after using social media.

8. I will be upset if I had to cut down the amount of time I spend using social media.

9. My family complain frequently of my preoccupation with social media.

10. My school grades have deteriorated because of my social media usage.

11. I often use social media while driving.

12. I often cancel meeting my friends because of my occupation with social 
media.

13. I find myself thinking about what happened in social media when I am away from them.

14. I feel my social media usage has increased significantly since I began using them.

Fourteen Likert-scale items were used in the questionnaire to estimate the dimensions underlying our key variable "social media addiction". Exploratory factor analysis with Varimax rotation was performed on these items to ascertain their underlying factors. As a result of the analysis, four items were discarded due to loadings under 0.5. All items were standardized to ensure they were on equal footing. Table 3 shows results of this analysis.

Table 3. Factor analysis of Social Media Addiction Scale (SMAS) with Varimax Rotation

\begin{tabular}{llllll}
\hline Factors & Mean & $S D$ & 1 & 2 & 3 \\
\hline Factor 1 & & & & & \\
1. Grades deteriorated because of SM. & 2.44 & 1.24 & 0.636 & & \\
2. I often use SM while driving. & 2.66 & 1.36 & 0.560 & \\
3. I cancel meeting my friends because of SM. & 1.67 & 0.97 & 0.787 & \\
4. I think about SM when I am away. & 3.03 & 1.24 & 0.582 & & \\
Factor 2 & & & & & 0.713 \\
5. I find myself using SM longer than intended. & 4.20 & 0.95 & & 0.620 & \\
6. I neglect my schoolwork because of SM. & 3.25 & 1.22 & & 0.509 & \\
7. I get irritated when interrupted using SM. & 3.25 & 1.20 & & 0.530 & \\
8. It's difficult to sleep after using SM. & 2.89 & 1.28 & & & 0.622 \\
Factor 3 & & & & & -0.762 \\
9. I find life boring without SM. & 3.98 & 1.09 & & & \\
10. Days pass by without the need to use SM.* & 2.66 & 1.32 & & & \\
Eigenvalue & & & 2.70 & 2.66 & 1.87 \\
\% of variance explained & & & 19.30 & 19.01 & 13.35 \\
Cronbach's alpha & & & 0.70 & 0.63 & 0.94 \\
\hline
\end{tabular}

Notes. Loadings $<0.50$ were suppressed, * Item wording was reversed for reliability analysis.

\subsection{Social Media Engagement}

According to Przybylski et al. (2013) numerous research studies indicate that people are not great at estimating the extent to which they use social media. As these interactions move inexorably on to mobile platforms, the challenge of quantifying levels of personal use will become increasingly complex. The Social Media Engagement Questionnaire (SMEQ) provides a solution to this problem, measuring the extent to which people's key daily activities tend to involve social media. The SMEQ scale consisted of five items on a scale with six response choices ranging from "Never" to "Seven" per week. Table 4 shows the means and standard deviations. In addition, it shows factor loadings consisting of a single dimension that will be used for the analysis. 
Table 4. Factor analysis of Social Media Engagement Questionnaire (SMEQ) with varimax rotation

\begin{tabular}{|c|c|c|c|}
\hline Variables & Mean & $S D$ & Factor Loadings \\
\hline \multicolumn{4}{|l|}{ In the past week } \\
\hline $\begin{array}{l}\text { 1. How many times have you used } \\
\text { social media } 15 \text { minutes before } \\
\text { going to bed? }\end{array}$ & 4.94 & 2.35 & .626 \\
\hline $\begin{array}{l}\text { 2. How many times have you used } \\
\text { social media during breakfast in the } \\
\text { morning? }\end{array}$ & 3.07 & 2.64 & .812 \\
\hline $\begin{array}{l}\text { 3. How many times you used social } \\
\text { media while eating dinner at night? }\end{array}$ & 3.67 & 2.62 & .836 \\
\hline $\begin{array}{l}\text { 4. How many times you used social } \\
\text { media within } 15 \text { minutes of waking } \\
\text { up in the morning? }\end{array}$ & 4.26 & 2.64 & .681 \\
\hline $\begin{array}{l}\text { 5. How many times you used social } \\
\text { media while eating lunch? }\end{array}$ & 3.00 & 2.64 & .809 \\
\hline Eigenvalue & & & 2.86 \\
\hline$\%$ of the variance explained & & & $\mathbf{5 7 . 3 7}$ \\
\hline Cronbach's alpha & & & 0.81 \\
\hline
\end{tabular}

Note. $\mathrm{n}=1327$, range $=1-7$.

\section{Results}

To answer the first research question about the effect of social media usage on academic performance I used regression analysis. The student's GPA was regressed on the time spent using social media with sex used as a control variable. As Table 5 shows the more time one spends using social media, the worse their GPA will be $(\beta$ $=-.085, p \leq .001)$. Furthermore, as the first block shows, there are no significant differences between males and females in this effect.

Table 5. Regressing GPA on time spent using social media with sex as control

\begin{tabular}{lllll}
\hline Variable & $B$ & $S E B$ & $\beta$ & $T$ \\
\hline Block 1 & & & & \\
Sex & -.59 & .035 & -.50 & -1.69 \\
Block 2 & & & & \\
Time Spent & -.020 & .007 & $-.085^{* *}$ & -2.80 \\
\hline
\end{tabular}

Note. Block $1, \mathrm{R}=.05, \mathrm{R}^{2}=.003, \mathrm{~F}=2.87, \mathrm{df}=1$.

Block $2, \mathrm{R}=.1, \mathrm{R}^{2}=.009, \mathrm{~F}=5.38, \mathrm{df}=2,{ }^{* *} \mathrm{p} \leq .001, \mathrm{n}=1327$.

The second research question asked about the effect of social media engagement on academic performance. To answer this question, the result from the factor analysis of SMEQ was used as an independent variable in a regression equation with sex as a control variable. As Table 5 shows, SMEQ has no significant effect on GPA. In addition, there were no sex differences in this effect. This means that being engaged with social media in and of itself does not impinge on a students' academic performance for both males and females. 
Table 6. Regressing GPA on SMEQ factor with sex as control

\begin{tabular}{lllll}
\hline Variable & $B$ & $S E B$ & $\beta$ & $T$ \\
\hline Block 1 & & & & \\
Sex & -.59 & .035 & -.51 & -1.707 \\
Block 2 & & & & \\
SMEQ & -.022 & .016 & -.041 & -1.38
\end{tabular}

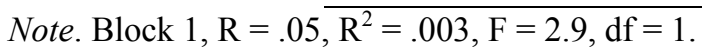

Block 2, $\mathrm{R}=.065, \mathrm{R}^{2}=.004, \mathrm{~F}=5.38, \mathrm{df}=2, \mathrm{n}=1327$.

The third research question asked about the effect of social media addiction on academic performance. To answer this question, results from the factor analysis performed on the Social Media Addiction Scale (SMAS) which resulted in three factors, were used as independent variables with sex as a control variable. As Table 6 shows, factor 1 was a significant negative predictor of a students' GPA $(\beta=-.101, p \leq .001)$. Factor 2 was also a significant negative predictor of GPA $(\beta=-.060, p \leq .05)$. Factor 3 showed no significant effects and sex also made no difference.

Table 7. Regressing GPA on SM addiction factors with sex as control

\begin{tabular}{lllll}
\hline Variable & $B$ & $S E B$ & $\beta$ & $T$ \\
\hline Block 1 & & & & \\
Sex & -.062 & .035 & -.53 & -1.783 \\
Block 2 Addiction & & & & \\
Factor 1 & -.055 & .016 & -.101 & $-3.34^{* *}$ \\
Factor 2 & -.032 & .016 & -.060 & $-1.94^{*}$ \\
Factor 3 & -.007 & .016 & -.012 & -.406 \\
\hline
\end{tabular}

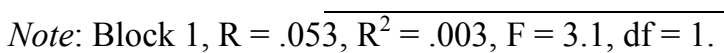

Block 2, $\mathrm{R}=.129, \mathrm{R}^{2}=.017, \mathrm{~F}=4.7, \mathrm{df}=2,{ }^{*} \mathrm{p} \leq .05,{ }^{* *} \mathrm{p} \leq .001, \mathrm{n}=1327$.

\section{Discussion}

This study investigated the effect of social media usage, engagement, and addiction on academic performance. First, the results show that the amount of time one spends using social effects academic performance in a negative way. The more time one spends using social media, the worse their academic performance. This suggests that the time devoted to using social media come more than likely at the expense of time that should have spent for academic purposes. Heavy users of social media probably do poorly in exams and assignments because they do not put enough time into it.

Second, I looked at the effect of social media engagement on academic performance. The SMEQ was subjected to factor analysis that revealed a single factor. This factor was used in regression analysis with sex as a control variable. Results show the SMEQ had no significant impact on academic performance. This indicates that, unlike social media usage, being engaged alone does not affect academic performance. Perhaps this is the result that engagement alone does not take much time, meaning one can be engaged without spending a significant amount of time using social media.

Lastly, the current research looked at social media addiction, and it's the effect on academic performance. Social Media Addiction Scale (SMAS) was used for this purpose. Factor analysis was again used to determine the dimensions of SMAS. The analysis yielded three factors. Two of these factors were negative predictors of academic performance. This means, the more a person shows symptoms of addiction, the worse their grades. This is not surprising since addiction implies heavy usage that previously showed the same negative effect on academic performance. 


\section{Conclusion}

This study investigated the effect of social media usage, engagement, and addiction on academic performance. Results show that the amount of time one spends using social media affects academic performance in a negative way. The amount of time one spends using social media is negatively correlated with their academic performance. In addition, the study looked at the effect of social media engagement on academic performance. Results show the SMEQ had no significant impact on academic performance. This outcome indicates that, unlike social media usage, being engaged alone does not affect academic performance. Finally, the study looked at social media addiction and its effect on academic performance. Social Media Addiction Scale (SMAS) was used for this purpose. Factor analysis was again used to determine the dimensions of SMAS. The analysis yielded three factors. Two of these factors were negative predictors of academic performance. This is not surprising since addiction implies heavy usage that previously showed the same negative effect on academic performance.

The definition and operationalization of social media addiction are still in its infancy. It is difficult at this stage to come up with policy suggestions. Instead, efforts should be focused on further refining the dimensions of the concept. We need to be sure that heavy social media usage is indeed a form of addiction as defined by the Diagnostic and Statistical Manual (DSM-5). Otherwise, it may be a form of dependency and less of an addiction. If this is the case, then measurement mechanisms should be refined to reflect the fact to enhance the validity of the procedures. Consequently, future work should emphasize the conceptualization and measurement issues before embarking on empirical research aimed at policy guidance.

\section{Limitations}

There are a few restrictions that might impinge upon the generalizability of the findings. Firstly, the cross-sectional data utilized in this study do not warrant any claim of any causal associations between the independent and dependent variables. Furthermore, the sample that had female to male ratio of 2:1 could skew the results by indicating more variance in the former compared to the latter. Maybe a quota sample with equal numbers of males and females should have been used to ensure that we do not get gender differences because of the irregular distribution.

Second, the definition of some constructs might limit the scope of the study. The main independent variables were based on self-reports. For example, the variable "time spent using social media" was measured by asking participants how much time they spend using social media on a typical day. Although this question measures usage time precisely, some uncertainty remains as to whether users are active all the time they are logged on to a particular application. Heavy and light users can be better analyzed in future studies by inquiring about the number of messages sent or received each day.

Third, the definition of typical social media use provided a viable empirical account to examine the research questions, but it might not accurately reflect the complexity of an individual's use patterns. It is possible that an individual uses several social media functions (e.g., Chat, post pictures, audio or video) each day. Researchers would benefit from constructing tools for capturing the complexity of social media and user patterns.

Finally, the fact that data collected for this study of social media use was restricted to college students should be taken into consideration. Investigating only college students' social media usage might not completely explain the electronic social networking activities in general. Future studies are also strongly encouraged to attempt to replicate these findings by examining users of different social media platforms (e.g., Twitter, Instagram, etc.) independently to account for the various features they offer.

\section{Acknowledgements}

This research was supported and funded by Kuwait University Research Grant no. (AM04/15).

\section{References}

Al-Menayes, J. (2014). The relationship between mobile media usage and academic performance in university students. New Media and Mass Communication, 25.

Dahlstrom, E., de Boor, T., Grunwald, P., \& Vockley, M. (2011). ECAR: National study of undergraduate students and information technology. Retrieved from http://net.educause.edu/ ir/library/pdf/ers1103/ers1103w.pdf

Fu-Yuan, H., \& Chiu, D. H. (2012). A model of the relationship between psychological characteristics, mobile phone addiction and use of mobile phones by Taiwanese university female students. Computers in Human Behavior, 2152-2159. 
Jacobsen, W., \& Forste, R. (2011). The Wired Generation: Academic and Social Outcomes of Electronic Media Use Among University Students. Cyberpsychology, Behavior, and Social Networking, 14(5), 275-280. http://dx.doi.org/10.1089/cyber.2010.0135

Junco, R., \& Cotton, S. R. (2011). Perceived academic effects of instant messaging use. Computers \& Education, 56, 370-378. http://dx.doi.org/10.1016/j.compedu.2010.08.020

Junco, R., \& Cotton, S. R. (2012). The relationship between multitasking and academic performance. Computers \& Education, 59, 505-514. http://dx.doi.org/10.1016/j.compedu.2011.12.023

Junco, R. (2013). Comparing actual and self-reported measures of Facebook use. Computers in Human Behavior, 29(3), 626-631. http://dx.doi.org/10.1016/j.chb.2012.11.007

Karpinski, A., Kirschner, P., Ozer, I., Mellott, J., \& Ochwo, P. (2013). An exploration of social networking site use, multitasking and academic performance among United States and European university students. Computers in Human Behavior, 29(3), 1182-1192. http://dx.doi.org/10.1016/j.chb.2012.10.011

Kirschner, P., \& Karpinski, A. (2010). Facebook and academic performance. Computers in Human Behavior, 26(6), 1237-1245. http://dx.doi.org/10.1016/j.chb.2010.03.024

Madden, M., Lenhart, A., Cortesi, S., Gasser, U., Duggan, M., Smith, A., ... Beaton, M. (2013). Teens, social media, and privacy. Pew Research Center.

Nadkarni, A., \& Hofmann, S. G. (2012). Why do people use Facebook. Personality and Individual Differences, 52(3), 243-249. http://dx.doi.org/10.1016/j.paid.2011.11.007

Pasek, J., More, E., \& Hargitti, E. (2009). Facebook and academic performance-Reconciling a media sensation with data. First Monday, 14(5). http://dx.doi.org/10.5210/fm.v14i5.2498

Paul, J., Baker, H., \& Cochran, J. (2012). Effect of online social networking on student academic performance. Computers in Human Behavior, 28(6), 2117-2172. http://dx.doi.org/10.1016/j.chb.2012.06.016

Rosen, L. D., Carrier, L. M., \& Cheever, N. A. (2013). Facebook and texting made me do it: Media-inducted task-switching while studying. Computers in Human Behavior, 29, 948-958. http://dx.doi.org/10.1016/j.chb.2012.12.001

Schulze, C., Scholer, L., \& Skiera, B. (2014). Not all fun and games: Viral marketing for utilitarian products. Journal of Marketing, 78(1), 1-19. http://dx.doi.org/10.1509/jm.11.0528

Skiera, B., Hinz, O., \& Spann, M. (2015). Social media and academic performance: Does the intensity of Facebook activity relate to good grades? Retrieved from http://www.sbr-online.de/ pdfarchive/einzelne_pdf/sbr_2015_jan_054-072.pdf

Wood, E., Zivcakova, L., Gentile, P., Archer, K., De Pasquale, D., \& Nosko, A. (2011). Examining the impact of distracting multitasking with technology on real-time classroom learning. Computers \& Education, 58, 365-374. http://dx.doi.org/10.1016/j.compedu.2011.08.029

Young, K. S. (2009). Internet addiction: The emergence of a new clinical disorder. Cyberpsychology and Behavior, 1, 237-244. http://dx.doi.org/10.1089/cpb.1998.1.237

\section{Copyrights}

Copyright for this article is retained by the author(s), with first publication rights granted to the journal.

This is an open-access article distributed under the terms and conditions of the Creative Commons Attribution license (http://creativecommons.org/licenses/by/3.0/). 